Progress in Chemical and Biochemical Research

Journal homepage: http://www.pcbiochemres.com/

Original Research Article

\title{
Green Synthesis and Biological Assessments of Silver Nanoparticles Using the Plant Extract of Crataegus sinaica Boiss. Fruits
}

\author{
Omar A. EL-Shahaby¹, Fikry M. Reicha², Maged Mohamed Nabil Aboushadi ${ }^{1}$, Mustafa M. \\ El-Zayat ${ }^{3 *}$ \\ ${ }^{1}$ Botany Department, Faculty of Science, Mansoura University, ET-35516, Mansoura, Egypt. \\ ${ }_{2}^{2}$ Physics Department, Faculty of Science, Mansoura University, ET-35516, Mansoura, Egypt. \\ ${ }^{3}$ Unit of Genetic Engineering and Biotechnology, Faculty of Science, Mansoura University, ET-35516, \\ Mansoura, Egypt.
}

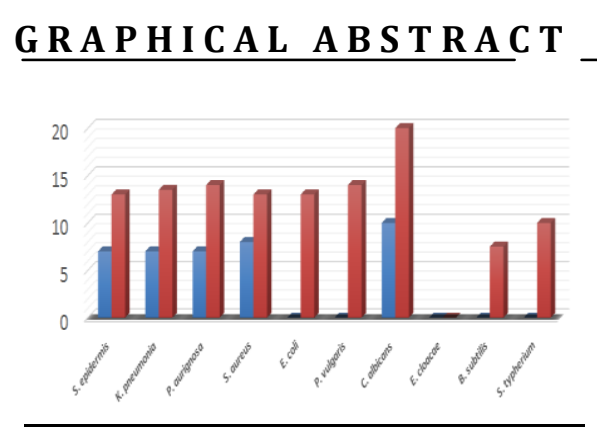

A R T I C L E I N F O

\section{Article history:}

Submitted: 2020-02-03

Revised: 2020-02-20

Accepted: 2020-04-12

Published: 2020-04-23

Manuscript ID: PCBR-2002-1080

\section{K E Y W O R D S}

Crataegus sinaica

Green synthesis

Phenolic \& flavonoid contents;

Biological assessments.

\section{A B S T R A C T}

Crataegus sinaica Boiss is a hawthorn plant that was found as a hybrid of two species, C. azarolus and C. monogyna, which grows vastly in the mountains of the Protectorate of St. Catherine, South Sinai, Egypt. The fruits of the plant are rich in primary and secondary metabolites, for instance reducing, total sugars, flavonoids, and phenols as demonstrated by the phytochemical analysis. The aqueous extract of the fruits of the plant was used to prepare the silver nanoparticles by green method, in which the reducing and total sugars facilitate the preparation step as they act as reducing and stabilizing agents. The nanoparticles of the plant were efficiently synthesized through mixing Crataegus sinaica fruits aqueous extract with silver nitrate solution at room temperature following the predetermined procedures for nanoparticle preparation. The prepared nanoparticles were identified by means of spectroscopic and analytical measurements i.e. UV-vis, IR, TEM, and zeta sizerzeta analyzer. The extract of the fruits of the plant and its silver nanoparticles were assessed as antimicrobial and antioxidant agents, in which the nanoparticle solution displayed the more potent activities against the diverse microbial species and potent antioxidant agent than the aqueous extract.

\section{INTRODUCTION}

\footnotetext{
The study of the synthesis of silver nanoparticles is increasingly interesting because of their inhibitory effect against several microbial strains [1]. Silver is well known in medicine for its wide range of applications, for instance, antibacterial activity against many pathogenic strains [2,3]. Many fairly expensive chemical and physical approaches, supposedly dangerous for the environmen $t$ and
}

impact various biological risks. There is a continuous search for inexpensive and eco-friendly routes for the synthesis of nanoparticles, using microorganisms [4,5] and plant extracts [6]. Green synthesis is a preferable method because of the slower kinetics, which offers better handling, controlling the growth and stabilization of the crystals. The eco-friendly technique to obtain the 
nanoparticles is a bottom-up attitude, in which the reduction step is the key reaction. The synthesis of nanoparticles from natural components such as plant extracts, vitamins, sugars, biodegradable polymers, and microorganisms as reducing and styling agents could be deliberated of interest for nanotechnology. Nevertheless, from the components mentioned above, the plant extracts of plant constituents such as leaves, roots, stems, latex, resin, and seeds appear to be the best candidates as they are appropriate for significant for green synthesis of nanoparticles [7].

The growth of Crataegus sinaica is extensively found in the mountainous region of the protectorate of St. Catherine in southern Sinai, Egypt, and identified as Za'rur or Za'rur Al-Awdiyah. The constitutes of the fruits are of rationally low levels of flavonoids and are made up of oligomeric and polymeric procyanidins. Flavonoids and procyanidins are deliberated to be the most essential constituents and are mainly liable for the pharmacological impacts of hawthorn $[8,9]$. The present study aimed to use the aqueous extract of the fruit of Crataegus sinaica as a source of reducing agents that can be used for the biosynthesis of pure metallic silver nanoparticles and to study the biological activities as antioxidant and antimicrobial agents.

\section{MATERIALS \& METHODS}

\section{Plant Materials and Extract Preparation}

The fruits of Crataegus sinaica were collected from their original environments at Saint Catherine Protectorate, South Sinai, Egypt. The taxonomical identification and authentication of the plant have proceeded acquiescent to Boulos [10]. $100 \mathrm{ml}$ deionized water was added to $10 \mathrm{~g}$ of the dried fruits of the plant and the mixture was heated at 70 ${ }^{\circ} \mathrm{C}$ for 30 minutes on a water bath. The extract obtained was filtered and stored at $4{ }^{\circ} \mathrm{C}$.

\section{phytochemical analysis \\ Total phenolic contents}

Total phenolics were estimated by means of the Folin Ciocalteu assay advanced by Wolfe et al [11] using Gallic acid as a standard.

\section{Total flavonoids contents}

The total flavonoids were estimated by means of colorimetric assessment as the procedure conveyed by Zhishen et al [12] using Catechin as a standard. The procedure involved the use of aluminum chloride.

Total soluble sugars and carbohydrate contents

The total contents of carbohydrates and soluble sugars were assessed following the procedure conveyed by Thayumanavan and Sadasivam [13] utilizing Glucose as a standard.

\section{Assessment of the Antioxidant Activity \\ Free radical scavenging activity via DPPH} assay

The influence of the antioxidant material on the radicals of DPPH radical was assessed by applying the process conveyed by Kitts et al. [14]. A serial dilution of each tested sample was prepared in

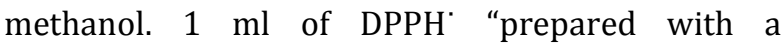
concentration of $0.135 \mathrm{mM}^{\prime}$ was added to each bottle of the prepared serial dilution of the tested sample. The samples were incubated at dark for 30 minutes and the absorbance was measured at $\lambda=$ $517 \mathrm{~nm}$. The percentage of remaining $\mathrm{DPPH}^{\text {' }}$ radicals of individually tested concentration at the steady-state was calculated from Eq. (1):

$\% \mathrm{DPPH}^{*}$ remaining $=\left[\mathrm{DPPH}^{\circ}\right]_{\mathrm{T}} /\left[\mathrm{DPPH}^{*}\right]_{\mathrm{T}=0} \mathrm{X} 100$

The values of the percentage remaining $\mathrm{DPPH}^{\circ}$ were plotted alongside the milligrams of the plant extract/ milligrams of DPPH to detect the number of antioxidants that are crucial to decrease the initial concentration of $\mathrm{DPPH}^{-}$by $50 \%\left(\mathrm{EC}_{50}\right)$ from the exponential curve [15]. The results were compared to those obtained by the standard "ascorbic acid".

\section{Synthesis of Metal Nanoparticles}


An aqueous solution of silver nitrate with a concentration of " $1 \mathrm{Mm}$ " was prepared and added to the preceding prepared aqueous extract of the fruits of Crataegus sinaica with continuous stirring at room temperature for 60 minutes. The change in color of the solution into reddish-brown indicated the formation of silver nanoparticles [16].

\section{Instrumental Analysis}

\section{UV-Visible Spectroscopy}

The UV-Vis spectra of the metal nanoparticles of the fruits of Crataegus sinaica was inspected on ATI Unicom UV-Vis. Spectrophotometer instrument. The scanned spectrum curve was recorded with wavelength ranged from $\lambda=200-800 \mathrm{~nm}$. The process depended on the conversion of the silver metal ions into nanoparticles and recording the UVVis spectra of the reaction mixture.

\section{Fourier Transform Infrared Spectroscopy}

The IR spectra were recorded for the aqueous extract and its silver nanoparticles to classify the functional groups that can contribute to the reduction process of silver ions and capping the generated nanoparticles. Mattson 5000 FTIR spectrometer was used for IR spectral analysis with wavenumbers ranged from $v=400-4000 \mathrm{~cm}^{-1}$ and a resolution of $8 \mathrm{~cm}^{-1}$ at room temperature.

\section{Transmission Electron Microscope (TEM) Measurement}

The morphology of the synthesized nanoparticles was inspected by TEM on (JEOL TEM1230, Japan) that was linked with a CCD camera at an accelerating voltage of $120 \mathrm{kV}$. The analyzed materials were prepared through the process involved dropping the silver nanoparticles suspension on carbon-coated copper grids and permitting the solvent evaporation with a slow rate overnight under vacuum at room temperature before the scanning and recording the TEM images.

\section{Microbial Susceptibility Testing Filter Paper Disc Assay}

The antimicrobial activity of the aqueous plant extract and its silver nanoparticles was assessed by the filter paper disc diffusion procedure [17] using inoculums of $10^{6}$ cells $/ \mathrm{ml}$ for bacterial species and $10^{8}$ cells $/ \mathrm{ml}$ for yeast strains to spread on nutrient agar and Sabouraud agar plates.

Filter paper discs of the type "Whatman no.1" with a diameter of " $6 \mathrm{~mm}$ " were sterilized and hence immersed in an aqueous plant extract sample and a solution of its nanoparticles. The discs were placed on the surface of the agar plates seeded with the tested pathogenic strains. The plates were incubated for $18-24$ hours at $37^{\circ} \mathrm{C}$ for bacteria and for 24-48 hours at $30^{\circ} \mathrm{C}$ for yeast [18].

Tested organisms

Bacterial species: "Staphylococcus aureus, Staphylococcus epidermis, Streptococcus pyogenes, Pseudomonas aeruginosa, Klebsiella pneumonia, Shigells spp., E. coli, Proteus vulgaris".

Yeast: Candida albicans

Stock cultures of the tested pathogenic strains were acquired from the microbiology lab at a Unit of Genetic Engineering and Biotechnology at Mansoura University.

\section{RESULTS}

\section{Synthesis of Silver Nanoparticles UV-Vis Spectroscopic Characterization}

The obtained silver nanoparticles of the fruits of Crataegus sinaica were characterized by UV-Vis spectra (Fig. 1). The formation of silver nanoparticles was perceived based on the change in the color of the fruit extract from faint brown into reddish-brown. It has been observed that the maximum absorption peak at about $436.0 \mathrm{~nm}$ is relevant to the individual surface plasmon resonance of the generated nanoparticles. The formed nanoparticles using the aqueous solution of the fruits of Crataegus sinaica were found to have reasonable stability. 


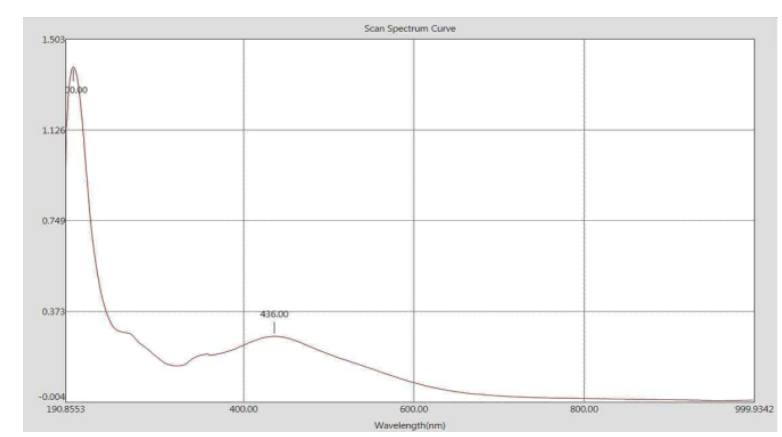

Fig. 1: UV-vis spectra of the prepared silver nanoparticles.

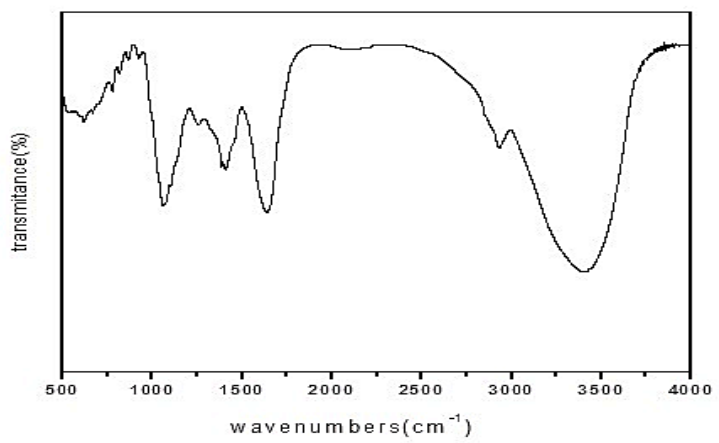

Fig. 2: FTIR spectrum of Crataegus sinaica fruits extract.

\section{FT-IR Spectroscopy}

The FT-IR spectral data supported the characterization of the prepared nanoparticles, the solution of nanoparticles has the possibility to reduce and stabilize the biomolecules in the aqueous extract of Crataegus sinaica fruits as depicted in Fig. 2). The FT-IR spectrum of Crataegus sinaica fruits extract revealed the characteristic absorption bands at $v=1068,1254,1404,1639$, 2932, 2925, and $3408 \mathrm{~cm}^{-1}$. The absorption bands in the region of $1025-1200 \mathrm{~cm}^{-1}$ are related to the $\mathrm{C}-0$ stretching vibration groups, the absorption bands ranged from $1620-1650 \mathrm{~cm}^{-1}$ are associated to the amidic carbonyl groups. In addition, a strong absorption broad-band at $3440 \mathrm{~cm}^{-1}$ was characterized for the $\mathrm{OH}$ groups present in phenolics and flavonoids.

\section{Transmission Electron Microscopy (TEM)}

TEM was used for the characterization of the morphology such as size, shape, and aggregation of the particles of the obtained nanoparticles. The TEM screening of silver nanoparticles of the aqueous extract of the fruits of Crataegus sinaica identified that the particles size is ranged from 16.06 to 28.19 $\mathrm{nm}$ at $100 \mathrm{~nm}$. In addition, the particles shape is spherical providing a large surface area and greater efficiency. The aggregation of the particles providing the better efficiency of the nanoparticle solution as a bioactive component. The prepared silver nanoparticles of the fruits of Crataegus sinaica were in the nano range as demonstrated in Fig. 3 and have been proven to be with good stability using zeta-potential as illustrated in Fig. 4.

\section{Phytochemical Analysis \\ Total Phenolic Contents}

The total phenolic contents in the aqueous extract of Crataegus sinaica fruits before and after the preparation of nanoparticles were reported as milligram gallic acid equivalent/gram of the dried fruits relative to the standard curve $\left(y=0.0062 x, r^{2}\right.$ $=0.988$ ). The total contents of the phenolic in the aqueous extract was 90.60 milligram gallic acid equivalent/gram of the dried fruits while in the prepared nano solution 42.6 milligram gallic acid equivalent/gram of the dried fruits. 


\section{Total Flavonoid Contents}

The total flavonoids were specified as milligram catechin equivalent per gram of the dried fruits relative to the standard curve $\left(\mathrm{y}=0.0029 \mathrm{x}, \mathrm{r}^{2}=\right.$ 0.99). The total contents of flavonoids were 27.22 milligram catechin equivalent/gram of the dried fruits while in the prepared nano solution 16.42 milligram catechin equivalent/gram of the dried fruits
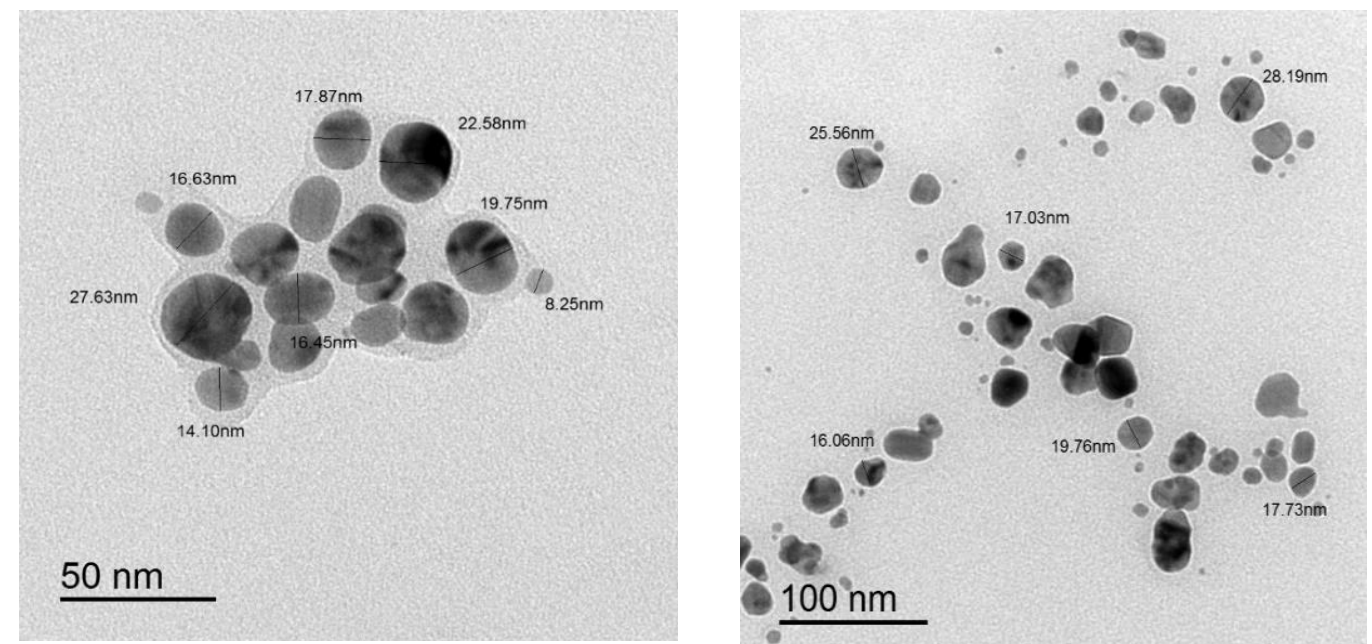

Fig. 3: Transmission electron microscopy images of silver nanoparticles derived from Crataegus sinaica using fruits extract.

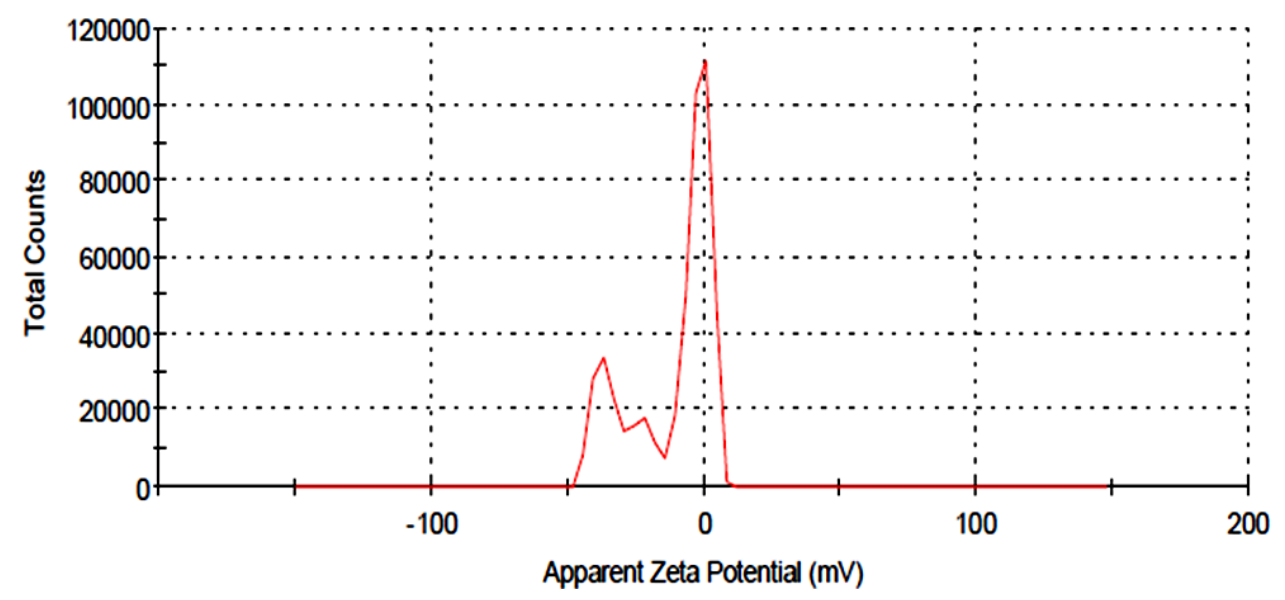

Fig. 4: Zeta potential of the prepared nanosilver using Crataegus sinaica fruits extract.

\section{Biological Evaluations}

\section{Antioxidant Activity}

The water extract of the Crataegus sinaica fruits showed $\mathrm{EC}_{50}=5.46 \mathrm{mg}$ extract $/ \mathrm{mg} \mathrm{DPPH}$, while the nanoparticle solution of Crataegus sinaica extract showed lower $\mathrm{EC}_{50}=21.15 \mathrm{mg}$ extract $/ \mathrm{mg} \mathrm{DPPH}$. Ascorbic acid showed $\mathrm{EC}_{50}=0.61 \mathrm{mg}$ extract $/ \mathrm{mg}$ DPPH.

\section{Antimicrobial Activity}

Microbial Susceptibility Testing (Disc Diffusion Assay)

Recently, the solutions of silver nanoparticles were reported as potent antimicrobial agents against diverse pathogenic microbial species $[19,20]$. Disc diffusion assay $[21,22]$ was applied for the evaluation of the antimicrobial potency of the aqueous extract of dried fruits of Crataegus sinaica 
and its silver nanoparticles against some pathogenic microbial species. The results of the antimicrobial screening are depicted in Table 1 . The results demonstrated that the formation of the nanoparticles enhanced the efficiency of the aqueous extract to inhibit the growth of the different pathogenic microbial species among the other aqueous extract itself.

Table 1. The results of antimicrobial screening of the aqueous extract of the fruits of wild Crataegus sinaica and its silver nanoparticles.

\begin{tabular}{ccccc}
\hline $\begin{array}{c}\text { Tested pathogenic } \\
\text { microbial species }\end{array}$ & $\begin{array}{c}\text { Streptomycin } \\
\text { (b) }\end{array}$ & $\begin{array}{c}\text { Clotrimazole } \\
\text { (c) }\end{array}$ & $\begin{array}{c}\text { Fruits } \\
\text { extract }\end{array}$ & $\begin{array}{c}\text { The silver nanoparticle } \\
\text { of fruits extract }\end{array}$ \\
\cline { 2 - 5 } $\begin{array}{c}\text { Staphylococcus } \\
\text { epidermis }\end{array}$ & 13 & $-\mathrm{ve}$ & 7 & 13 \\
Klebsiella pneumonia & $-\mathrm{ve}$ & -ve & 7 & 13.5 \\
Pseudomonas aurignosa & 18 & -ve & 7 & 14 \\
Staphylococcus aureus & 17 & -ve & 8 & 13 \\
E. coli & 16 & $-\mathrm{ve}$ & $-\mathrm{ve}$ & 14 \\
Proteus vulgaris & $-\mathrm{ve}$ & $-\mathrm{ve}$ & $-\mathrm{ve}$ & 20 \\
Candida albicans & $-\mathrm{ve}$ & 15 & 10 & $-\mathrm{ve}$ \\
Enterobacter cloacae & $-\mathrm{ve}$ & $-\mathrm{ve}$ & $-\mathrm{ve}$ & 7.5 \\
Bacillus subtilis & 15 & -ve & -ve & 10
\end{tabular}

$a$ : Zone of inhibition, including the diameter of the filter disc (6.0 mm). Streptomycin $(b)$ and Clotrimazole $(c)$ (antibiotic standards for bacterial and fungal species, respectively).

\section{DISCUSSION}

An efficient procedure for green synthesis of silver nanoparticles using the aqueous extract of the dried fruits of Crataegus sinaica was used. The reddish-brown color formation is associated with the surface Plasmon resonance with absorption maxima at $394 \mathrm{~nm}$ characterized by the generation of metal nanoparticles [23,24]. The aqueous extract of the dried fruits of Crataegus sinaica is rich with active secondary metabolites for instance, flavonoids and phenolics. Flavonoids are well known to play a vital role as a reductant in the synthesis of silver nanoparticles [25,26]. Accordingly, the estimated flavonoids and phenolics content in the aqueous extract of Crataegus sinaica fruits strongly support its potential in the bioreduction of $\mathrm{Ag}^{+}$to $\mathrm{Ag}^{\circ}$ and that has been approved by measuring the content of phenolics and flavonoids after nano synthesis where this content was reduced due to it utilization on the biosynthesis and consequently, the antioxidant activity decreased than the that of the original extract. Similarly, the predominant reducing sugars in the extract have pronounced impacts in bioreduction process [26,27]. Consistently, the insoluble contents carbohydrates, for example, starch reflected the capping possessions of the extract [28].

The FTIR spectrum characterized the diverse absorption bands revealing the characteristic groups that have been changed due to the chemical transformations in the functional groups resulted from the bioreduction process and the evolution of the chemical constitutes of the nanoparticles [26,29]

Silver metal ions and silver-constructed nanoparticles are exceedingly toxic to microbial species with potent biocidal impact against the tested bacterial and fungal strains due to the smaller size of the particles provided the increase in the surface area and hence increase the reactivity of the sample. Silver nanoparticles synthesized from the 
fruits of the plant extracts as reductants exhibited broad antimicrobial spectrum [30] The antimicrobial activity has guaranteed that the synthesized nanoparticles using the aqueous extract of Crataegus sinaica fruit demonstrated a great bactericidal and fungicidal impact for the synthesized nanoparticles on the pathogenic tested microorganisms than the aqueous extract itself or a low concentration of a solution of silver nanoparticles. This assay demonstrated the synergy between the water extract of Crataegus sinaica fruits and silver nanoparticles.

In conclusion, the extracted aqueous solution of the dried fruits of Crataegus sinaica was utilized to

\section{REFERENCES}

[1] S.U. Khan, T.A. Saleh, A. Wahab, M.H.U. Khan, D. Khan, W.U. Khan, A. Rahim, S. Kamal, F.U. Khan, S. Fahad, Nanosilver: new ageless and versatile biomedical therapeutic scaffold, Int. J. Nanomedicine. 13 (2018) 733.

[2] A. Taraszkiewicz, G. Fila, M. Grinholc, J. Nakonieczna, Innovative strategies to overcome biofilm resistance, Biomed Res. Int. 2013 (2012).

[3] G. Franci, A. Falanga, S. Galdiero, L. Palomba, M. Rai, G. Morelli, M. Galdiero, Silver nanoparticles as potential antibacterial agents, Molecules. 20 (2015) 8856-8874.

[4] Z. Wang, Q. Li, Y. Chen, B. Cui, Y. Li, F. Besenbacher, M. Dong, The ambipolar transport behavior of WSe 2 transistors and its analogue circuits, NPG Asia Mater. 10 (2018) 703-712.

[5] A.P. Reverberi, N.T. Kuznetsov, V.P. Meshalkin, M. Salerno, B. Fabiano, Systematical analysis of chemical methods in metal nanoparticles synthesis, Theor. Found. Chem. Eng. 50 (2016) 59-66.

[6] N. Skandalis, A. Dimopoulou, A. Georgopoulou, N. Gallios, D. Papadopoulos, D. Tsipas, I. Theologidis, N. Michailidis, M. Chatzinikolaidou, The effect of silver nanoparticles size, produced using plant extract from Arbutus unedo, on their antibacterial efficacy, Nanomaterials. 7 (2017) prepare silver nanoparticles by green technique. The results of the biological evaluations revealed the great impact of the synthesized nanoparticles using silver ions on the antioxidant and antimicrobial characteristics to enhance the results and increase the efficiency of the synthesized nanoparticles than the aqueous extract itself. This approach seems to be one of the best models to be used in the therapeutic management of infectious diseases.

\section{CONFLICT OF INTEREST}

The authors affirm no conflict of interest

178.

[7] A.T. Refaat, A.A. Shahat, N.A. Ehsan, N. Yassin, F. Hammouda, E.A. Tabl, S.I. Ismail, Phytochemical and biological activities of Crataegus sinaica growing in Egypt, Asian Pac. J. Trop. Med. 3 (2010) 257-261.

[8] S. Ahmad, S. Munir, N. Zeb, A. Ullah, B. Khan, J. Ali, M. Bilal, M. Omer, M. Alamzeb, S.M. Salman, Green nanotechnology: a review on green synthesis of silver nanoparticles-an ecofriendly approach, Int. J. Nanomedicine. 14 (2019) 5087.

[9] A. Moustafa, M. Zaghloul, S. Mansour, M. Alotaibi, Conservation Strategy for protecting Crataegus x sinaica against climate change and anthropologic activities in South Sinai Mountains, Egypt, Catrina Int. J. Environ. Sci. 18 (2019) 1-6.

[10] L. Boulos, Flora of egypt, Al Hadara Publishing Cairo, 2005.

[11] K. Wolfe, X. Wu, R.H. Liu, Antioxidant activity of apple peels, J. Agric. Food Chem. 51 (2003) 609-614.

[12] J. Zhishen, T. Mengcheng, W. Jianming, Research on antioxidant activity of flavonoids from natural materials, Food Chem. 64 (1999) 555-559.

[13] B. Thayumanavan, S. Sadasivam, Physicohemical basis for the preferential uses of certain rice varieties, Plant Foods Hum. Nutr. 
34 (1984) 253-259.

[14] D.D. Kitts, A.N. Wijewickreme, C. Hu, Antioxidant properties of a North American ginseng extract, Mol. Cell. Biochem. 203 (2000) 1-10.

[15] I. Parejo, C. Codina, C. Petrakis, P. Kefalas, Evaluation of scavenging activity assessed by Co (II)/EDTA-induced luminol chemiluminescence and DPPH·(2, 2-diphenyl1-picrylhydrazyl) free radical assay, J. Pharmacol. Toxicol. Methods. 44 (2000) 507512.

[16] S. Pirtarighat, M. Ghannadnia, S. Baghshahi, Green synthesis of silver nanoparticles using the plant extract of Salvia spinosa grown in vitro and their antibacterial activity assessment, J. Nanostructure Chem. 9 (2019) 1-9.

[17] Z.R. Zad, S.S.H. Davarani, A. Taheri, Y. Bide, A yolk shell_Fe304@PA-Ni@Pd/Chitosan nanocomposite -modified carbon ionic liquid electrode as a new sensor for the sensitive determination of fluconazole in pharmaceutical preparations and biological fluids, Journal of Molecular Liquids, 253(2018) 233-40.

[18] S. Sardari, G. Amin, R.G. Micetich, M. Daneshtalab, Phytopharmaceuticals. Part 1. Antifungal activity of selected Iranian and Canadian plants, Pharm. Biol. 36 (1998) 180188.

[19] N. Durán, M. Durán, M.B. De Jesus, A.B. Seabra, W.J. Fávaro, G. Nakazato, Silver nanoparticles: A new view on mechanistic aspects on antimicrobial activity, Nanomedicine Nanotechnology, Biol. Med. 12 (2016) 789-799.

[20] L. Salvioni, E. Galbiati, V. Collico, G. Alessio, S. Avvakumova, F. Corsi, P. Tortora, D. Prosperi, M. Colombo, Negatively charged silver nanoparticles with potent antibacterial activity and reduced toxicity for pharmaceutical preparations, Int. J. Nanomedicine. 12 (2017) 2517.

[21] O.A. El-Shahaby, M. El-Zayat, A. El-Fattah, M.M. El-Hefny, Evaluation of the biological activity of Capparis spinosa var. aegyptiaca essential oils and fatty constituents as Anticipated Antioxidant and Antimicrobial Agents, Prog. Chem. Biochem. Res. 2 (2019) 211-221.

[22] 0. El-Shahaby, M. El-Zayat, R. Rabei, H.S. Aldesuquy, Phytochemical constituents, antioxidant activity and antimicrobial potential of Pulicaria incisa (lam.) DC as a folk medicinal plant, Prog. Chem. Biochem. Res. 2 (2019) 222227.

[23] D.M. Maestri, V. Nepote, A.L. Lamarque, J.A. Zygadlo, Natural products as antioxidants, Phytochem. Adv. Res. 37 (2006) 105-135.

[24] R. Jalilian, M. Shahmari, A. Taheri, K. Gholami, Ultrasonic-assisted micro solid phase extraction of arsenic on a new ion-imprinted polymer synthesized from chitosan-stabilized pickering emulsion in water, rice and vegetable samples, Ultrason Sonochem, 61(2020) 104802.

[25] E.M. Egorova, A.A. Revina, Synthesis of metallic nanoparticles in reverse micelles in the presence of quercetin, Colloids Surfaces A Physicochem. Eng. Asp. 168 (2000) 87-96.

[26] S. Ghosh, S. Patil, M. Ahire, R. Kitture, S. Kale, K. Pardesi, S.S. Cameotra, J. Bellare, D.D. Dhavale, A. Jabgunde, Synthesis of silver nanoparticles using Dioscorea bulbifera tuber extract and evaluation of its synergistic potential in combination with antimicrobial agents, Int. J. Nanomedicine. 7 (2012) 483.

[27] K.I. Batarseh, Anomaly and correlation of killing in the therapeutic properties of silver (I) chelation with glutamic and tartaric acids, J. Antimicrob. Chemother. 54 (2004) 546-548.

[28] V.K. Sharma, R.A. Yngard, Y. Lin, Silver nanoparticles: green synthesis and their antimicrobial activities, Adv. Colloid Interface Sci. 145 (2009) 83-96.

[29] M. Tammer, G. SInfrared and Raman characteristic group frequencies: tables and charts, (2004).

[30] O. El-Shahaby, M. El-Zayat, E. Salih, I.M. ElSherbiny, F.M. Reicha, Evaluation of antimicrobial activity of water infusion plantmediated silver nanoparticles, J Nanomed Nanotechol. 4 (2013) 2. 
HOW TO CITE THIS ARTICLE

O.A. EL-Shahaby, F.M. Reicha, M. M. Nabil Aboushadi, M.M. El-Zayat, Green Synthesis and Biological Assessments of Silver Nanoparticles Using the Plant Extract of Crataegus sinaica Boiss. Fruits, Prog. Chem. Biochem. Res. 2020, 3(2),105-113.

DOI: $10.33945 /$ SAMI/PCBR.2020.2.3

URL: http://www.pcbiochemres.com/article_106598.html

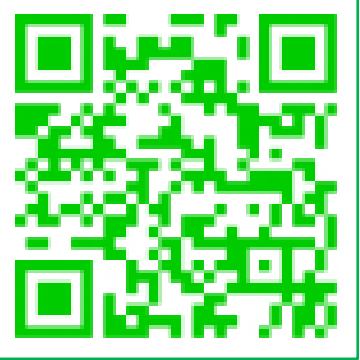

